\title{
PERGESERAN MAKNA TRADISI TEMU MANTEN PADA PERKAWINAN ADAT JAWA DI DUSUN WONOSARI DESA TEBANG KACANG KECAMATAN SUNGAI RAYA KABUPATEN KUBU RAYA
}

\author{
Eka Ermawati, Ika Rahmatika Chalimi, Haris Firmansyah \\ Program Studi Pendidikan Sejarah FKIP Untan Pontianak \\ Email: ekaermawati77@student.untan.ac.id
}

\begin{abstract}
Marriage is a form of sacred bond in unifying relationships,namely the relationship between men and women and also a bond in uniting two different families.in Javanese traditional it has a unique traditional, namely Temu Manten. This study aimed to describe the shift in the meaning of Temu Manten in Javanese traditional marriages in Wonosari Hamlest, Tebang Kacang Village, Sungai Raya District, Kubu Raya Regency. This study used a qualitative method with a descriptive-ethnographic approach. Data collection techiques used were observation guidelines, interview guidelines, and documentation tools. The data analysis during collection, data presentation or data display, and drawing conclusions or verification. Validation data used were the source and technique triangulation. Based on research conducted by Temu Manten Tradition, starting from the procession of the Bride and Groom, Balangan Gantal, Wiji Dadi, Sindur, Dulangan, Kacar-Kucur, and Sungkeman procession. There was a shift in meaning in bridal procession, which originally used Kembar Mayang and now it does not use it. And in Wiji Dadi procession, which originally used Kembar Mayang and now it does not use it. And in Wiji Dadi procession, where the groom's feet are washed by his family, now his wife washes his feet. The conclusion in this study is that those who experience a shift in meaning in the procession of the bride and groom which originally used Kembar Mayang, now does not use it. And in Wiji Dadi procession, the firsh one who washes the the feed of the groom's family and now his feed are washed by his wife.
\end{abstract}

Keywords: Tradition, Wedding, Java.

\section{PENDAHULUAN}

Kebudayaan merupakan hasil dari apa yang pernah dilakukan manusia dan dijadikan sebuah kebiasaan yang mengandung makna dan nilai tertentu, seperti hal nya kebudayaan dalam tradisi pernikahan. Banyak suku bangsa di Indonesia yang memiliki berbagai jenis ciri khas budaya dalam tradisi pernikahan. Seperti pada masyarakat suku Jawa yang mempunyai tradisi pernikahan unik dan berbeda dengan suku lainya. "Koentjaraningrat (2009:144) berpendapat bahwa, budaya adalah kesatuan antara sistem gagasan, tindakan dan hasil karya manusia dalam kehidupan manusia yang menjadi jati diri manusia dengan belajar". Sesuatu hal yang dilakukan secara sadar ataupun tidak sadar, yang membawa kepada pengaruh positif akan menjadi kebudayaan, seperti hal nya kebudayaan yang ada di tradisi perkawinan yang dilakukan oleh masyarakat dengan maksud dan tujuan agar membawa dampak kebaikan.

Menurut Goodenough 1970 (Roger, 1981:6) "Perkawinan adalah suatu perjanjian yang menghasilkan suatu hubungan dimana seseorang (laki-laki dan perempuan, badan hukum atau perseorangan, secara pribadi atau melalui perwakilan) mempunyai hak yang berkelanjutan untuk melakukan hubungan seksual dengan seorang perempuan, hak ini 
didahulukan dari pada hak untuk melakukan persetubuhan yang saat ini dimiliki atau yang kemudian diperoleh oleh orang lain terhadap wanita tersebut (kecuali mereka yang melakukan transaksi), sampai akad yang dihasilkan dari transaksi tersebut berakhir dan wanita tersebut dianggap layak untuk melahirkan seorang anak.

Suku Jawa memiliki budaya yang unik dalam upacara perkawinan. Salah satu keunikan budaya Jawa adalah tradisi Temu Manten. Tradisi Temu Manten adalah prosesi yang menggambarkan bagaimana proses bertemunya sepasang pengantin (pria dan wanita) dimana pengantian pria didampingi oleh beberapa orang seperti keluarga dekatnya dan diserahkan kepada pengantin wanita, dan pengantin wanita menyambut pengantin pria di depan pintu rumahnya. Dalam prosesi ini terdapat banyak makna salah satunya adalah memohon doa restu agar kehidupan mereka dijauhkan dari hal-hal yang tidak baik, selain itu mereka juga harus bisa saling berbagi dan menghargai agar kehidupan mereka menjadi tenang dan mampu untuk menghadapi masalah apupun yang terjadi.

Seiring dengan kemajuan zaman yang semakin modern dan semakin canggih lambat laun makna pada tradisi bisa saja mengalami pergeseran, hal ini bisa terjadi dan tidak bisa dipungkiri oleh keadaan. Pergeseran makna yaitu, dimana keadaan ritual yang semula sudah diterapkan dan dilestarikan mengalami perubahan oleh keadaan sekitar, seperti faktor lingkungan, agama, ilmu pengetahuan dan lain sebagainya. Chaer (dalam Fika, 2018) menjelaskan bahwa, terjadinya perubahan, pergeseran, dan perkembangan makna tersebut disebabkan oleh beberapa hal, antara lain perkembangan ilmu pengetahuan dan teknologi, sosial budaya, dan perbedaan tanggapan. Ferry (2000: 269) berpendapat bahwa, makna merupakan unsur terpenting dalam komunikasi lisan (antara pembicara dan pendengar) dan komunikasi tertulis (antara penulis dan pembaca). Penggunaan bahasa secara produktif (berbicara dan menulis) dan reseptif (mendengar dan membaca) tetap mengutamakan makna dalam komunikasi melalui bahasa.
Tujuan dari penelitian ini untuk mendeskripsikan prosesi Тети Manten, pergeseran makna tradisi Teти Manten, dan keterlibatan anggota masyarakat pada perkawinan adat Jawa di Dusun Wonosari Desa Tebang Kacang Kecamatan Sungai Raya Kabupaten Kubu Raya.

\section{METODE PENELITIAN}

Metode penelitian yang digunakan adalah metode deskriptif kualitatif, Menurut Sutopo (2006:48) penelitian kualitatif mengutamakan makna, berfokus pada data yang berkualitas dengan analisis kualitatif. Metode kualitatif tidak memfokuskan kepada banyaknya data, tetapi kepada kualitas datanya. Menurut (Nawawi, 2015 : 67), metode deskriptif adalah prosedur pemecahan masalah yang diselidiki dengan menggambar/melambangkan keadaan terkini dari subjek/objek penelitian (orang, institusi, masyarakat dan lain-lain) berdasarkan fakta yang muncul atau apa adanya.

Penelitian ini mengambil lokasi di Dusun Wonosari, Desa Tebang Kacang, Kecamatan Sungai Raya, Kabupaten Kubu Raya. Peneliti melakukan pengamatan yang cermat terhadap prosesi pernikahan Adat Jawa di Dusun Wonosari, Desa Tebang Kacang, Kecamatan Sungai Raya, Kabupaten Kubu Raya. Sumber data difokuskan pada hasil observasi yang dilakukan peneliti di lapangan dan hasil wawancara yang dilakukan peneliti dengan narasumber.

Teknik pengumpulan data yang digunakan yaitu observasi pada saat resepsi perkawinan, wawancara yang dilakukan dengan narasumber yang bersangkutan pada pelaksanaan acara pernikahan, dan dokumentasi. Observasi dilakukan pada saat berlangsungnya prosesi Temu Manten, pada pernikahan salah satu warga di Dusun Wonosari. Informan yang diperoleh peneliti ini yaitu dari Para sesepuh yang memipin acara pernikahan, keluarga pengantin, tokoh Agama, dan Kepala Dusun yang ada di lingkungan setempat. Dokumentasi merupakan pengambilan gambar dilapangan, seperti foto mempelai pengantin, foto bahan dan alat yang digunakan, dan foto pada saat acara tersebut sedang berlangsung.

Analisis data penelitian dalam penelitian ini dilakukan secara kualitatif 
dengan tiga alur yaitu, reduksi, penyajian data, dan validasi data. Reduksi data adalah proses penyaringan dan pemusatan perhatian peneliti melalui pemilihan fokus yang ketat untuk studi lebih lanjut, pemusatan, pengikhtisaran hasil pengumpulan data, pengorganisasian data, hingga siap untuk di analisis lebih lanjut setelah pengumpulan data selesai secara keseluruhan. Menurut Sutopo (2006:114-115) penyajian data adalah kumpulan informasi organisasi, deskripsi dalam bentuk narasi yang memungkinkan kesimpulan dari penelitian yang dilakukan. Dan validasi data merupakan tindak lanjut dari reduksi data dan penyajian data sehingga dapat ditarik kesimpulan dan penelitian memiliki kesempatan untuk menerima masukan simpulan akhir tidak akan terjadi sampai pengumpulan data berakhir.

\section{HASIL PENELITIAN DAN PEMBAHASAN}

\section{Hasil}

Tradisi Temu Manten adalah tradisi yang dilakukan oleh orang Jawa, ketika mereka menikahkan anak-anak mereka, baik anak laki-laki maupun anak perempuan. Dengan tujuan meminta keselamatan, pada kehidupan keluarga anak mereka nantinya. tradisi Temu Manten ini terdapat berbagai macam rangkaian prosesi, dimulai dari prosesi yang pertama yaitu, Iring-Iringan Pengantin, Balangan Gantal, Wiji Dadi, Sindur, Dulangan, Kacar-Kacur, dan yang terakhir Sungkeman.

\section{a. Prosesi Temu Manten yang Terjadi di Dusun Wonosari}

Prosesi Temu Manten yang terjadi di Dusun Wonosari Desa Tebang Kacang, dimulai dari prosesi iring-iringan Pengantin yaitu, pengantin pria diiring-iring bersama keluarganya dan dihantarkan ke rumah pengantin wanita. Yang kedua prosesi Balangan Gantal, yaitu prosesi pelemparan gulungan daun sirih yang dilempar sebanyak tiga kali secara bergantian, pada prosesi ini pengantin wanita menyambut kedatangan pengantin pria didepan rumah pengantin wanita, kemudian melempar gulungan daun sirih ke pengantin pria begitu juga sebaliknya. Yang ketiga prosesi Wiji Dadi, yaitu prosesi menginjak telur ayam diatas takir yang dialasi dengan beras dan berbagai bumbu lainnya seperti bawang merah dan putih, serta kemiri kemudian diinjak oleh pengantin pria, setelah menginjak telur kaki pengantin pria dicuci oleh pengantin wanita. Yang keempat prosesi Sindur, yaitu prosesi dimana sepasang pengantin berjalan menuju pelaminan dan ditarik dari depan oleh ayah penganti wanita menggunakan kain batik, dan di pegang pundaknya oleh ibu dari pengantin wanita, kemudian berjalan menuju depan pelaminan dan melanjutkan prosesi selanjutnya.

Prosesi yang kelima prosesi Dulangan, yaitu prosesi dimana sepasang pengantin makan bersama dan saling suap-menyuap sebanyak tiga kali secara bergantian. Yang keenam prosesi Kacar-Kucur, yaitu prosesi dimana seorang suami memberikan nafkah kepada istrinya, nafkah yang diberikan yaitu berupa beras, uang, dan bumbu dapur yang merupakan kebutuhan pokok dalam kehidupan sehari-hari. Beras, uang, dan bumbu lainnya dimasukan kedalam satu tempat yang dinamakan klowoh kemudian diberikan kepada istrinya. Dan yang terakhir prosesi Sungkeman, yaitu prosesi dimana kedua pengantin meminta maaf dan bersimpuh dihadapan kedua orang tua mereka secara bergantian.

\section{b. Makna yang Mengalami Pergeseran Pada Prosesi Temu Manten}

Pada hasil penelitian ini ditemukan makna pada prosesi yang mengalami pergeseran, yaitu pada prosesi iring-iringan Pengantin. Dahulu iring-iringan pengantin menggunakan anyaman Kembar Mayang, tetapi saat ini tidak karena sudah tidak ada yang bisa menganyam Kembar Mayang ini dan bahannya juga sulit didapatkan di Desa Tebang Kacang. Selain itu prosesi Wiji Dadi juga mengalami pergeseran, dahulu yang mencuci kaki pengantin pria keluarganya sekarang harus istrinya, pergeseran ini terjadi karena memang pada dasarnya kewajiban istri yaitu melayani suami. Meskipun ada makna pada prosesi Temu Manten yang mengalami pergeseran, tidak menjadikan alasan masyarakat Dusun Wonosari untuk melupakan atau meninggalkan tradisi tersebut. 


\section{c. Upaya yang Dilakukan Masyarakat Dalam Melestarikan Tradisi Temu Manten}

Upaya yang dilakukan masyarakat, dalam melestarikan tradisi ini terlihat dari antusias masyarakat Dusun Wonosari dalam melaksanakan tradisi ini pada perkawinan anak-anaknya. Begitu juga dengan masyarakat lainya masih sangat antusias, dalam meramaikan dan membantu dalam pelaksanaan tradisi ini.
Upaya tersebut dilakukan untuk meminimalisir pergeseran makna pada prosesi Temu Manten, yang saat ini sudah jarang dilakukan oleh orang- orang suku Jawa pada umumnya. Namun ada sebagian suku Jawa yang masih melaksanakan upacara Temu Manten ini dengan berbagai alas an dan tujuan untuk memohon dan mengharapkan kebaika pada kehidupan anakanaknya nanti setelah hidup berumah tangga.

Tabel 1. Hasil Observasi Tradisi Temu Manten di Dusun Wonosari Desa Tebang Kacang.

\begin{tabular}{|c|c|c|c|}
\hline No & $\begin{array}{l}\text { Prosesi Temu Manten } \\
\text { Zaman Dahulu }\end{array}$ & $\begin{array}{c}\text { Prosesi Temu Manten Hasil } \\
\text { observasi }\end{array}$ & Keterangan \\
\hline 1 & $\begin{array}{l}\text { Prosesi Iring-Iringan Kembar } \\
\text { Mayang yaitu prosesi } \\
\text { mengiring pengantin pria ke } \\
\text { kediaman pengantin wanita } \\
\text { dan membawa Anyaman } \\
\text { Kembar Mayang yang terbuat } \\
\text { dari daun Janur Kelapa dan } \\
\text { diberikan kepada keluarga } \\
\text { pengantin wanita. }\end{array}$ & $\begin{array}{l}\text { Prosesi Iring-Iringan } \\
\text { Pengantin yaitu pengantin } \\
\text { pria diiring-iring dan } \\
\text { dihantarkan ke kediaman } \\
\text { pengantin wanita. }\end{array}$ & $\begin{array}{lr}\text { Masih dilaksanakan } \\
\text { tetapi } & \text { tidak } \\
\text { menggunakan } & \text { Kembar } \\
\text { Mayang. } & \end{array}$ \\
\hline 2 & $\begin{array}{l}\text { Prosesi Balangan Gantal yaitu } \\
\text { prosesi pelemparan gulungan } \\
\text { daun sirih yang dilempar } \\
\text { sebanyak tiga kali secara } \\
\text { bergantian. }\end{array}$ & $\begin{array}{l}\text { Prosesi Balangan Gantal } \\
\text { yaitu prosesi pelemparan } \\
\text { gulungan daun sirih yang } \\
\text { dilempar sebanyak tiga kali } \\
\text { secara bergantian. }\end{array}$ & $\begin{array}{l}\text { Masih dilaksanakan dan } \\
\text { tidak ada pergeseran. }\end{array}$ \\
\hline 3 & $\begin{array}{l}\text { Prosesi Wiji Dadi yaitu } \\
\text { prosesi menginjak telur ayam } \\
\text { diatas bunga yang dimasukan } \\
\text { dalam takir, kemudian kaki } \\
\text { pengantin pria dicuci oleh } \\
\text { keluarganya, adiknya atau } \\
\text { kakak kandungnya. }\end{array}$ & $\begin{array}{l}\text { Prosesi Wiji Dadi yaitu } \\
\text { prosesi menginjak telur ayam } \\
\text { diatas bunga yang dimasukan } \\
\text { dalam takir, kemudian kaki } \\
\text { pengantin pria dicuci oleh } \\
\text { pengantin wanita. }\end{array}$ & $\begin{array}{l}\text { Masih dilaksanakan dan } \\
\text { ada pergeseran, yang } \\
\text { dulunya kaki pengantin } \\
\text { pria dicuci oleh } \\
\text { keluarganya sekarang } \\
\text { dicuci oleh istrinya. }\end{array}$ \\
\hline 4 & $\begin{array}{l}\text { Prosesi Sindur merupakan } \\
\text { prosesi dimana sepasang } \\
\text { pengantin berjalan menuju } \\
\text { pelaminan dan dipimpin oleh } \\
\text { Ayah dari pengantin wanita. }\end{array}$ & $\begin{array}{l}\text { Prosesi Sindur merupakan } \\
\text { prosesi dimana sepasang } \\
\text { pengantin berjalan menuju } \\
\text { pelaminan dan dipimpin oleh } \\
\text { Ayah dari pengantin wanita. }\end{array}$ & $\begin{array}{l}\text { Masih dilaksanakan dan } \\
\text { tidak ada pergeseran. }\end{array}$ \\
\hline 5 & $\begin{array}{l}\text { Prosesi Dulangan yaitu prosesi } \\
\text { dimana sepasang pengantin } \\
\text { makan bersama dan saling } \\
\text { suap-menyuap. }\end{array}$ & $\begin{array}{l}\text { Prosesi Dulangan yaitu } \\
\text { prosesi dimana sepasang } \\
\text { pengantin makan bersama } \\
\text { dan saling suap-menyuap. }\end{array}$ & $\begin{array}{l}\text { Masih dilaksanakan dan } \\
\text { tidak ada pergeseran }\end{array}$ \\
\hline 6 & Prosesi Kacar-Kucur adalah & Prosesi Kacar-Kucur adalah & Masih dilaksanakan dan \\
\hline
\end{tabular}




\begin{tabular}{lllll}
\hline & prosesi dimana seorang suami \\
memberikan nafkah kepada & $\begin{array}{l}\text { prosesi secara simbolis tidak ada pergeseran } \\
\text { istrinya. }\end{array}$ & $\begin{array}{l}\text { bahwa seorang suami wajib } \\
\text { memberikan nafkah kepada } \\
\text { istrinya. }\end{array}$ & \\
\hline 7 & Prosesi Sungkeman yaitu & Prosesi Sungkeman yaitu Masih dilaksanakan dan \\
prosesi kedua pengantin & prosesi kedua pengantin tidak ada pergeseran. \\
meminta maaf dan bersimpuh & meminta maaf dan & \\
dihadapan kedua orang tua & bersimpuh dihadapan kedua \\
mereka secara bergantian. & $\begin{array}{l}\text { orang tua mereka secara } \\
\text { bergantian. }\end{array}$ & \\
\hline
\end{tabular}

\section{Pembahasan}

Tradisi Temu Manten di Dusun Wonosari Desa Tebang Kacang, Kecamatan Sungai Raya Kabupaten Kubu Raya. Merupakan tradisi turun temurun peninggalan leluhur, yang dilaksanakan sejak kedatangan orang Jawa yang merantau ke Kalimantan Barat sebelum kemerdekaan Indonesia. Hasan Hanafi (dalam Agus Subandi, 2018:46) berpendapat bahwa, tradisi adalah semua warisan masa lalu yang ada pada masa sekarang dan termasuk dalam budaya masa kini. Tradisi adalah kebiasaan yang telah dilakukan oleh nenek moyang dan masih dilestarikan oleh generasi berikutnya.

\section{a. Prosesi Temu Manten}

Tradisi Temu Manten merupakan Upacara Adat yang dilakukan oleh masyarakat Jawa di berbagai daerah pada pernikahan anaknya, Temu Manten ini mempunyai makna yaitu pertemuan antara pengantin pria dan pengantin wanita yang diiring-iring ke kediaman mempelai wanita. Masyarakat mengartikan bahwa arti dari Tradisi Temu Manten ini merupakan simbol dari pertemuan antara pengantin pria dan pengantin wanita. Di Dusun Wonosari, prosesi pada Tradisi Temu Manten maknanya masih sama seperti di daerah lainnya, yang didalamnya terdapat tujuh prosesi yaitu Prosesi Iring-Iringan Pengantin, Balangan Gantal, Wiji Dadi, Sindur, Dulangan, KacarKucur, dan Sungkeman. Edi Sedyawati (2010: 429) menyatakan bahwa, tradisitradisi Jawa secara garis besar terbagi menjadi tiga pokok, yaitu sistem upacara daur hidup dan sistem upacara daur waktu, adat pergaulan, dan kesenian. Tradisi-tradisi tersebut telah ditegakkan di masa lalu (yang sering kali tidak dapat dilacak ketepatan waktunya) dan dilestarikan hingga sekarang dari waktu ke waktu disesuaikan dengan tuntutan zaman.

Prosesi iring-iringan merupakan iringiringan Pengantin merupakan prosesi dimana pengantin pria, berjalan bersama keluarganya menuju kerumah pengantin wanita. Pada prosesi ini pengantin pria yang sudah sampai dirumah pengantin wanita, akan disambut oleh pengantin Wanita didepan pintu masuk rumah pengantin Wanita bersama keluarga dari pengantin Wanita.

Setelah prosesi Iring-Iringan kemudian dilanjutkan dengan prosesi Balangan Gantal, Balangan Gantal merupakan prosesi melempar cinta yang dilambangkan dengan Gantal atau gulungan Daun Sirih. Pelemparan ini dilakukan sebagai tanda bertemunya kedua pengantin tersebut, dan prosesi ini dilakukan didepan pintu rumah atau pintu masuk Tarub di kediaman mempelai Wanita. Alda Soraya (2020:550) menyatakan bahwa, dalam prosesi Balangan Gantal mempelai saling berhadapan dengan jarak tiga sampai lima langkah dan saling melempar ikatan sirih. Pengantin pria melempar sirih ke dada pengantin wanita begitu juga sebaliknya, mempelai pria melempar gulungan sirih ke pengantin wanita dan didampingin kedua orang tua mereka.

Kemudian prosesi yang ketiga yaitu Wiji Dadi atau Menginjak Telur, Wiji Dadi merupakan prosesi menginjak Telur yang dilakukan oleh pengantin Pria, Telur yang digunakan dalam prosesi ini jika ada menggunakan Telur Ayam Kampung, namun jika tidak ada bias digantikan dengan Telur Ayam biasa agar tidak memberatkan Tuan Rumah. Agus Subandi (2017:53) berpendapat 
bahwa, prosesi Wiji Dadi artinya pengantin pria yang menginjak telur ayam artinya dia siap bertanggung jawab, membangun rumah tangga, siap memberi nafkah dan merawat istrinya, serta bisa menjadi pelindung dan teladan yang baik bagi keluarga. Sedangkan pengantin wanita yang membasuhi kaki pengantin pria memiliki makna bahwa seorang istri harus patuh kepada suami dan siap melayani suaminya.

Prosesi keempat yaitu Sindur, Sindur merupakan prosesi dimana ayah dari pengantin Wanita menggendong kedua pengantin tersebut, dengan Selendang atau jika tidak ada bisa digantikan dengan Kain Batik. Dimana ayah dari pengantin Wanita ini berjalan didepan kedua pengantin tersebut, kemudian ibu dari pengantin wanita memegang pundak mereka berdua dari belakang. Agus Subandi (2017:54) makna dari prosesi Sindur ini bahwa kedua orang tua mereka menunjukan jalan kebenaran dan kebaikan yang dapat menjadikan keluarga mereka menjadi keluarga yang baik.

Prosesi yang kelima yaitu Dulangan, Dulangan prosesi, dimana kedua pengantin makan bersama dan saling menyuapi secara bergantian sebanyak masing-masing tiga kali. Dalam prosesi ini perlengkapan yang dibutuhkan yaitu Nasi yang dicampur dengan lauk pauk menjadi satu, kemudian air putih untuk minum sebanyak dua gelas dan air cuci tangan. Alda Soraya (2020:552) Prosesi Dulangan adalah prosesi makan bersama yang dilakukan oleh sepasang pengantin tersebut, dalam prosesi ini kedua mempelai saling menyuapi makanan dan minuman yang telah disiapkan satu sama lain sebanyak tiga kali suapan.

Prosesi yang keenam yaitu KacarKucur, Kacar-Kucur merupakan prosesi dimana seorang suami memberikan nafkah kepada istrinya, yang disimbolkan dengan sebuah Rantang/Klowoh (jika ada) yang di isi dengan Beras, Uang, Cabai Kering dan bumbu dapur lainya. Makna dari prosesi ini yaitu sebagai seorang suami harus memberi nafkah kepada istrinya berapapun hasil atau pendapatannya. Suwarno (dalam Bayu, 2018:36) menyatakan bahwa, Prosesi kacarkacur adalah prosesi dimana pengantin pria memberikan hasil dari kerja kerasnya kepada pengantin wanita yang dimasukan kedalam suatu tempat yang disebut Tampa Kaya yang berisi kedelai, kacang, padi, beras kuning, jamu dlingo bengle, bunga dan beberapa mata uang yang berbeda nilainya.

Dan yang terakhir adalah prosesi Sungkeman, Sungkeman merupakan prosesi yang paling terakhir atau penutup. Dimana kedua penganti saling bersimpuh didepan kedua orang tua mereka secara bergantian. Alda Soraya (2020:553) Sungkeman adalah prosesi terakhir dari Temu Manten, kedua mempelai memohon restu kepada semua orang tua yang telah duduk berbaris. Kedua mempelai duduk bersimpuh menghadap orang tua sambil bersalaman dan orang tua memberikan nasehat-nasehat kepada kedua mempelai. Prosesi ini dilakukan orang tua mempelai pria dan mempelai wanita secara bergantian.

\section{b. Makna Prosesi yang Mengalami Pergeseran}

Pada prosesi Temu Manten yang berlangsung di Dusun wonosari Desa Tebang Kacang terdapat dua prosesi yang mengalami pergeseran makna, yaitu pada prosesi iringiringan pengantin dan prosesi Wiji Dadi.

Prosesi iring-iringan pengantin sebelum mengalami pergeseran, dahulu menggunakan anyaman Kembar Mayang. Kembar Mayang ini dibawa oleh pengantin pria dan diberikan kepada pengantin wanita. Kembar Mayang adalah benda yang memiliki simbol dan makna. Kembar Mayang merupakan pesan bagi para pengantin baru, bahwa mereka tetap bisa menjaga pernikahan meski ada hambatan dan tantangan. Kembar Mayang juga merupakan pedoman atau nasehat dalam mengarungi kehidupan baru (Indra dan Manugeren, 2019: 3).

Prosesi iring-iringan Kembar Mayang mengalami pergeseran disebabkan oleh beberapa faktor, diantaranya yaitu. Bahan yang susah dicari, tidak ada pengrajin yang ahli dalam membuat anyaman Kembar Mayang, dan kondisi sosial ekonomi masyarakat sekitar.

Kemudian prosesi selanjutnya yang mengalami pergeseran yaitu prosesi Wiji Dadi, menurut Alda Soraya (2020:551), Wiji Dadi adalah prosesi menginjak telur mentah yang dilakukan oleh mempelai pria, 
mempelai pria melepas alas kaki untuk melakukan prosesi ini dan menginjak telur mentah sampai pecah kemudian setelah itu mempelai wanita membasuh kaki mempelai pria dengan air kembang setaman.

Sebelum mengalami pergeseran prosesi Wiji Dadi ini, setelah pengantin pria menginjak telur yang mencuci kaki bukan istrinya melainkan keluarga dari pengantin pria. Tetapi setelah pemandu prosesi Temu Manten ini berganti generasi makan yang wajib mencuci kaki pengantin pria yaitu istrinya sendiri. Pergeseran ini disebabkan karena pada dasarnya kewajiban seorang istri yaitu melayani suaminya oleh sebab itu pemandu prosesi Teтu Manten yang bertugas saat meminta agar yang mencuci kaki pengantin pria yaitu istrinya.

\section{c. Upaya Pelestarian yang Dilakukan Masyarakat \\ Dalam pelaksanaan Tradisi lokal yaitu} Tradisi Temu Manten yang ada di Dusun Wonosari Desa Tebang Kacang, terdapat upaya masyarakat dalam melestarikan tradisi ini. Hal tersebut masih terlihat jelas dengan antusias masyarakat yang masih sering melaksanakan tradisi ini pada perkawinan anaknya, dan juga antusias masyarakat lainya yang terlibat dalam pelaksanaan tradisi ini terlihat dengan cara mereke berpartisipasi membantu berlangsungnya prosesi pada Temu Manten ini dari dimulainya acara sampai acara selesai. M. Natsir, dkk. (2014:11), berpendapat bahwa, pelaksanaan upacara adat sebagai bentuk penghormatan terhadap warisan budaya leluhur yang telah diwariskan secara turun temurun perlu dilestarikan. Tanpa adanya upaya pelestarian dari masyarakat, budaya leluhur berupa upacara adat akan punah dan tinggal cerita. Agar hal tersebut tidak terjadi, maka generasi muda saat ini harus lebih perduli dengan budaya warisan nenek moyang, agar kebudayaan yang ada tetap bisa dilihat dan diketahui oleh generasi penerus dimasa depan.

\section{KESIMPULAN DAN SARAN}

\section{Kesimpulan}

Berdasarkan hasil penelitian dan datadata yang diperoleh tentang Pergeseran Makna Tradisi Temu Manten Pada Perkawinan Adat Jawa Di Dusun Wonosari Desa Tebang Kacang Kecamatan Sungai Raya Kabupaten Kubu Raya, maka dapat disimpulkan bahwa. Dalam perkawinan adat Jawa terdapat berbagai macam upacara adat yang biasanya masih dilaksanakan, salah satunya yaitu upacara Temu Manten. Pada upacara Temu Manten terdapat berbagai macam prosesi, namun seiring berkembangnya zaman prosesi pada Temu Manten ini mengalami pergeseran makna yaitu pada prosesi Iring-Iringan Pengantin, dahulu iring-iringan ini menggunakan Anyaman Kembar Mayang tetapi sekarang tidak. Pergeseran ini disebabkan karena pada saat ini sudah sulit ditemukan orang yang pandai dalam membuat Kembar Mayang sehinggal lambat laun Kembar Mayang pada prosesi Temu Manten ini dihilangkan dan hanya menggunakan iring-iringan biasa.

\section{Saran}

Diharapkan kepada sesepuh, tokoh masyarakat, dan masyarakat umum dapat memberikan motivasi kepada generasi muda dan generasi penerus terkait budaya lokal. Hal ini ditunjukan agar budaya tersebut dapat terus dilestarikan bahkan di era kehidupan modern yang sedikit demi sedikit dapat mengikis budaya lokal. Dengan upaya tetap melaksanakan upacara Teти Manten pada pernikahan anak-anaknya.

\section{DAFTAR RUJUKAN}

Adenan, F. (2000). Makna Dalam Bahasa. Jurnal Humaniora. Vol 12 (3), 261-269. https://doi.org/107.22146/jh.698.

Keesing R. M., \& Gunawan, S. (1981). Antropologi Budaya:Suatu Perspektif Kontemporer.Penerbit Erlangga.Jakarta.

Koentjaraningrat. (2009). Pengantar Ilmu Antropologi. Penerbit Rineka Cipta. Jakarta. 
Natsir, M. (2014). Nilai-Nilai Budaya Dalam Upacara Haulan. Yogyakarta: Kepel Press.

Nawawi, H. (2015). Metode Penelitian Bidang Sosial. Yogyakarta. Penerbit Gadjah Mada University Press.

Panjaitan, I. P. \& Manugeren, M. (2019). Symbolic Meaning Of Kembar Mayang In Javanese Wedding Ceremony At Desa Medan Sinembah Kecamatan Tanjung Morawa Kabupaten Deli Serdang. Jurnal of Language. Vol 1 (1) 2019.

https://doi.org/10.30743/jol.v1i1.1123.

Pratama, B. A. \& Wahyuningsih, N. (2018). Pernikahan Adat Jawa Di Desa Nengahan, Kecamatan Bayat, Kabupaten Klaten. Jurnal UNS. Vol 2 (1) 2018. https://doi.org/10.20961/hsb.v2i1.19604.

Rahma, F. A., Nuzula, N. A., Safitri, V., \& Sunaryo. (2018). Pergeseran Makna: Analisis Peyorasi dan Ameliorasi Dalam
Konteks Kalimat. Jurnal Pendidikan Bahasa Dan Sastra Indonesia. vol 1 (2). https://doi.org/10.21776/ub.hastawiyata. 2018.001.02.01.

Sedyawati, E. (2010). Budaya Indonesia: Kajian Arkeologi, Seni, dan Sejarah. Jakarta: Raja Grafindo Persada.

Soraya, A. (2020). Analisis Makna Pada Prosesi Pernikahan Adat Jawa "Temu Manten" Di Samarinda Kajian Semiotik Rolland Barthes. Jurnal UNEJ. Vol. 1 (1), 548-555, 2020. https://jurnal.unej.ac.id/index.php/prosid ing/article/view/20017.

Subandi, A. (2018). Nilai Spiritual Tradisi Temu Manten Adat Jawa Dalam Perspektif Masyarakat Buddhis. Jurnal Pendidikan, Sains, Sosial dan Agama. Vol 4 (1), 43-56, 2018.

Sutopo. (2006). Metodologi Peneliti an Kualitatif. Surakarta. Penerbit: Universitas Sebelas Maret. 
